https://helda.helsinki.fi

\title{
Vascular endothelial growth factor signaling in development and disease
}

\section{Karaman, Sinem}

2018-07-15

Karaman , S , Leppänen , V-M \& Alitalo , K 2018 , ' Vascular endothelial growth factor signaling in development and disease ' , Development , vol. 145 , no. 14 , 151019 . https://doi.org/10.1242/dev.1510

http://hdl.handle.net/10138/300456

https://doi.org/10.1242/dev.151019

publishedVersion

Downloaded from Helda, University of Helsinki institutional repository.

This is an electronic reprint of the original article.

This reprint may differ from the original in pagination and typographic detail.

Please cite the original version. 


\title{
Vascular endothelial growth factor signaling in development and disease
}

\author{
Sinem Karaman*, Veli-Matti Leppänen* and Kari Alitalo ${ }^{\ddagger}$
}

\begin{abstract}
Vascular endothelial growth factors (VEGFs) are best known for their involvement in orchestrating the development and maintenance of the blood and lymphatic vascular systems. VEGFs are secreted by a variety of cells and they bind to their cognate tyrosine kinase VEGF receptors (VEGFRs) in endothelial cells to elicit various downstream effects. In recent years, there has been tremendous progress in elucidating different VEGF/VEGFR signaling functions in both the blood and lymphatic vascular systems. Here, and in the accompanying poster, we present key elements of the VEGF/VEGFR pathway and
\end{abstract}

Wihuri Research Institute and Translational Cancer Biology Program, Biomedicum Helsinki, University of Helsinki, Helsinki 00290, Finland.

*These authors contributed equally to this work

${ }^{\ddagger}$ Author for correspondence (kari.alitalo@helsinki.fi)

(D) S.K., 0000-0002-0719-1773; K.A., 0000-0002-7331-0902 highlight the classical and newly discovered functions of VEGF signaling in blood and lymphatic vessel development and pathology.

\section{KEY WORDS: VEGF, Receptor tyrosine kinase, Vessels}

\section{Introduction}

The vascular circulatory system evolved to enable the shuttling of nutrients, oxygen or waste products between various tissues, employing networks of blood vessels and lymphatic vessels that arise by the processes of angiogenesis and lymphangiogenesis, respectively. Over the past few decades, vascular endothelial growth factors (VEGFs) and their receptors (VEGFRs) have emerged as the principal drivers of angiogenesis and lymphangiogenesis, and hence the development and maintenance of both of these vascular systems. The field of VEGF/VEGFR signaling was established by seminal papers describing the functional role of VEGFA (which was initially named as VPF, for vascular permeability factor) and the identification of VEGFA as an endothelial growth factor

\section{Development}
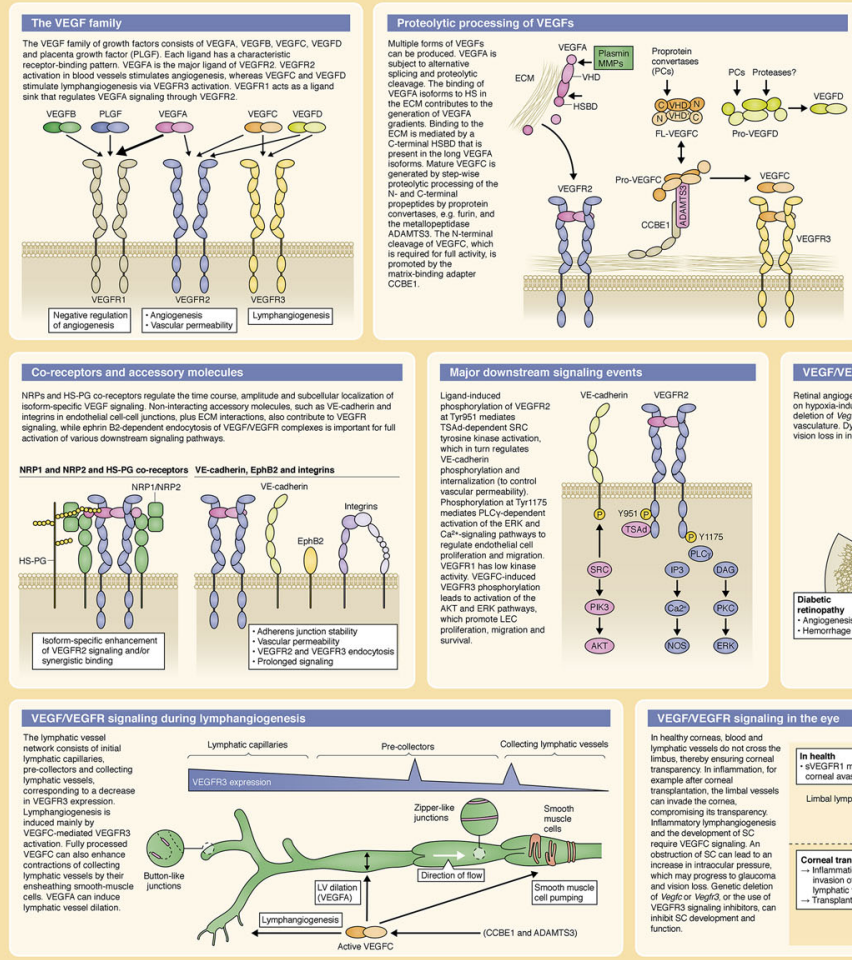

Sinem Karaman, Veli-Matti Leppänen and Kari Alitalo

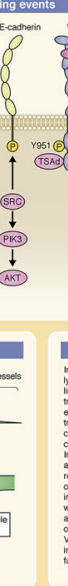

Vascular endothelial growth factor signaling
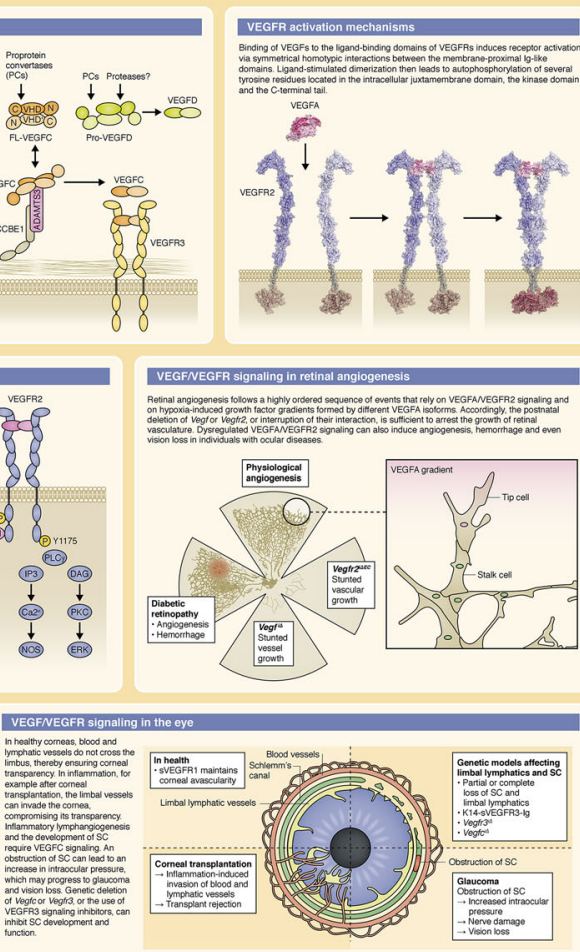
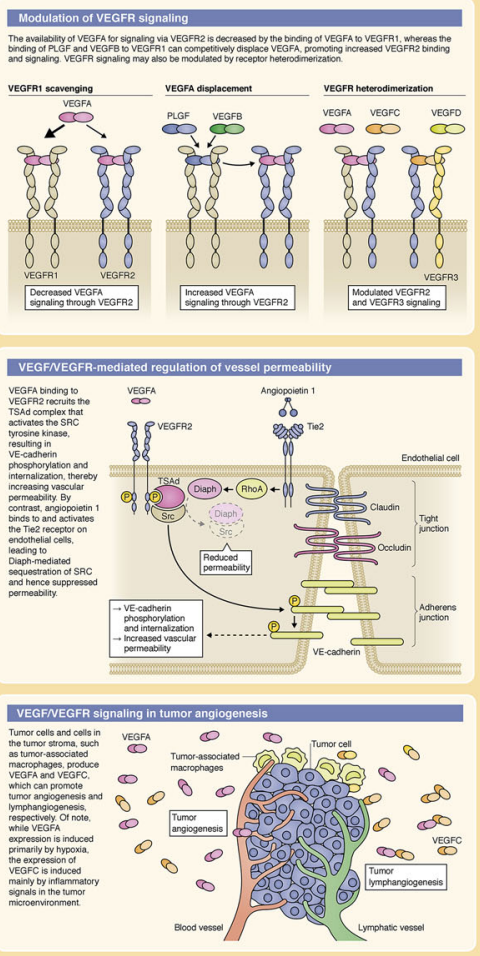
(Leung et al., 1989; Senger et al., 1983). These discoveries were followed by the identification of the receptor tyrosine kinases VEGFR1 (FLT1), VEGFR2 (KDR/FLK1) and VEGFR3 (FLT4) (Matthews et al., 1991; Pajusola et al., 1992; Shibuya et al., 1990; Terman et al., 1991), which were later shown to bind to VEGFs. Since then, a multitude of studies has provided insights into the mechanisms and regulation of VEGF/VEGFR signaling.

As organ development and function relies heavily on the parallel development and maintenance of organ-specific vascular systems, understanding the role and contribution of VEGF/VEGFR signaling to these processes is essential for furthering our understanding of development. In addition, it is now clear that VEGF signaling is essential for the physiological function of many tissues and plays important roles in the pathogenesis of diseases such as cardiovascular disease, cancer and ocular disease. Here and in the accompanying poster, we provide an overview of VEGF/VEGFR signaling system components and explain the roles of each signaling axis in development and disease.

\section{An overview of VEGFs and their receptors}

In mammals, VEGFA is the prototype member of the VEGF family of proteins, which also includes VEGFB, VEGFC, VEGFD and placenta growth factor (PLGF) (Joukov et al., 1997; Leung et al., 1989; Maglione et al., 1991; Olofsson et al., 1996; Park et al., 1994). VEGFs are formed from antiparallel polypeptides that form a cystine-knot homodimer covalently linked by two intermolecular disulfide bonds. VEGFs have characteristic receptor-binding patterns and they stimulate angiogenesis and lymphangiogenesis via one or two of the three endothelial receptor tyrosine kinases VEGFR1, VEGFR2 and VEGFR3 (Matthews et al., 1991; Pajusola et al., 1992; Shibuya et al., 1990; Terman et al., 1991). VEGFRs consist of seven immunoglobulin (Ig) homology domains that contain the ligand-binding part and a split tyrosine kinase domain, which transduces the growth factor signals. VEGFA signaling in blood vascular endothelial cells is mediated predominantly via activation of VEGFR2 (Simons et al., 2016). VEGFB, PLGF and VEGFA are high-affinity ligands of VEGFR1, but because of the relatively weak VEGFR1 kinase activity, this receptor serves as a negative regulator of VEGFA signaling by limiting the amount of free VEGFA available for binding to VEGFR2 homodimers (Hiratsuka et al., 1998; Joukov et al., 1997; Leung et al., 1989; Maglione et al., 1991; Olofsson et al., 1996; Park et al., 1994). By contrast, VEGFC and VEGFD stimulate VEGFR3 activation, which plays an indispensable role in lymphangiogenesis (Tammela and Alitalo, 2010).

\section{Alternative splicing and processing of VEGF family members}

Multiple species of VEGFs that have different affinities for VEGFRs, co-receptors and heparan sulfate (HS) proteoglycans can be generated by alternative RNA splicing or proteolytic processing. In humans, alternative RNA splicing results in the generation of the four major VEGFA isoforms VEGFA $_{121}, \mathrm{VEGFA}_{165}, \mathrm{VEGFA}_{189}$ and VEGFA $_{206}$ ) that have different affinities for neuropilin co-receptors and HS proteoglycans on the cell surface and in the pericellular matrix (Houck et al., 1992; Leung et al., 1989). Additional splicing in the last exon and programmed stop codon read-through can generate further isoforms, which are of unknown significance (Harris et al., 2012; Xin et al., 2016). The VEGFR1-specific ligands VEGFB and PLGF are very similar in many respects; they exist as two major isoforms that show differences in solubility, and HS and NRP1 binding (Migdal et al., 1998; Olofsson et al., 1996).

Most of the VEGFA isoforms are bound to HS on the cell surface or in the extracellular matrix (ECM) (Houck et al., 1992).
This contributes to the generation of VEGFA gradients that are important for the development and patterning of the vascular system. The serine protease plasmin and a subset of matrix metalloproteinases can induce the release of proteolytically cleaved VEGFA from the ECM; soluble VEGFA can thus be produced by both alternative splicing and proteolytic cleavage (Houck et al., 1992; Lee et al., 2005; Plouët et al., 1997). An excess of soluble VEGFA is also sequestered by soluble VEGFR1 (sVEGFR1) that is generated from an alternatively spliced VEGFR1 mRNA (Kendall and Thomas, 1993).

Whereas VEGFA isoforms are mainly formed through alternative splicing, the different forms of VEGFC and VEGFD are generated by proteolytic processing. VEGFC is synthesized as a precursor in which the central VEGF homology domain (VHD) is flanked by $\mathrm{N}$ - and C-terminal propeptides. Proteolytic removal of the propeptides increases VEGFC affinity for VEGFR3, and the resulting mature protein can also activate the major angiogenic receptor VEGFR2 (Joukov et al., 1997). During its secretion, VEGFC undergoes cleavage in the $\mathrm{C}$-terminal region, resulting in pro-VEGFC. The N-terminal cleavage that then results in full activity of VEGFC is regulated by collagen- and calcium-binding EGF domains 1 (CCBE1) protein and executed by a disintegrin and metalloprotease with thrombospondin motifs-3 (ADAMTS3) protease (Jeltsch et al., 2014; Le Guen et al., 2014; Roukens et al., 2015). Specific proteases that activate VEGFD by cleavage of the N-terminal propeptide are so far unknown, suggesting that VEGFD has evolved to function in distinct angiogenic and lymphangiogenic responses (Bower et al., 2017; Bui et al., 2016; McColl et al., 2003).

\section{VEGF pathway activation mechanisms}

\section{Ligand-induced VEGFR homodimerization and activation}

VEGF ligands bind to the Ig-like domains 1-3 of their cognate VEGFRs, thereby inducing the activation of VEGFRs via symmetrical homotypic interactions between their membraneproximal Ig-like domains 4-7 (Leppanen et al., 2013; MarkovicMueller et al., 2017; Yang et al., 2010). As an exception, VEGFB, which is a weak agonist of VEGFR1, does not appear to interact with domain 3 and cannot induce similar homotypic interactions (Anisimov et al., 2013). Conservation of the ligand-binding sites and the homotypic interactions provides the structural basis of VEGFR heterodimerization (Leppanen et al., 2013; Markovic-Mueller et al., 2017; Yang et al., 2010). VEGFRs can also form dimers in the absence of ligand, but ligand binding changes transmembrane domain conformation, thereby stimulating kinase domain phosphorylation (Sarabipour et al., 2016). Of note, antibodies that block VEGFR homotypic interactions, and hence VEGFR activation, provide promising tools for the therapeutic modulation of VEGFR2 and VEGFR3 activity (Kendrew et al., 2011; Tvorogov et al., 2010).

\section{Heterodimerization of VEGFRs}

VEGFRs can also heterodimerize, leading to slightly different signaling outcomes. For example, ligand-stimulated VEGFR1/ VEGFR2 heterodimerization attenuates VEGFR2 phosphorylation, but increases VEGFR1 signaling (Cudmore et al., 2012; Huang et al., 2001). VEGFC, and apparently to some extent also VEGFA, can stimulate VEGFR2/VEGFR3 heterodimerization in the tip cells of angiogenic sprouts, presumably increasing angiogenic activity (Dixelius et al., 2003; Nilsson et al., 2010).

\section{VEGFA signaling can be modulated by VEGFB and PLGF}

PLGF and VEGFB can induce signaling through VEGFR1 in pericytes and in other cells (Eilken et al., 2017; Muramatsu et al., 2010; Selvaraj et al., 2015; Shibuya and Claesson-Welsh, 2006) but, 
mechanistically, a more important feature of these ligands is that their binding to VEGFR1 increases VEGFA availability for VEGFR2 binding and activation (Hiratsuka et al., 1998; Kivela et al., 2014; Park et al., 1994; Robciuc et al., 2016). PLGF and VEGFA can also form heterodimers when expressed in the same cells, which may further modulate VEGFA signaling through VEGFR2 (Cao et al., 1996). In addition, although VEGFR1 deletion in embryos is lethal, the removal of only the VEGFR1 tyrosine kinase domain is compatible with vascular development, suggesting that membrane-bound VEGFR1 can act as a decoy receptor for VEGFA (Hiratsuka et al., 1998).

\section{Neuropilin co-receptors and accessory molecules regulate VEGFR signaling}

A number of VEGF-interacting co-receptors and non-interacting accessory molecules regulate the time course, subcellular localization and amplitude of VEGFR signaling. The semaphorin receptor neuropilin 1 (NRP1), for example, is also a VEGFR2 co-receptor, and it regulates VEGFA-mediated endothelial permeability by modulating VEGFR2 phosphorylation and downstream signaling (Becker et al., 2005; Fantin et al., 2017; Soker et al., 1998). VEGFA, VEGFR2 and NRP1 bind weakly to HS proteoglycans alone, but show synergistic binding to HS proteoglycans when presented together in various combinations. This increases VEGFA-stimulated VEGFR2 activation and ERK1/2 phosphorylation in endothelial cells (Teran and Nugent, 2015). NRP2 is an important co-receptor for VEGFR3 in the lymphatic vasculature, and HS proteoglycans have also been shown to contribute to VEGFC signaling (Johns et al., 2016; Kärpänen et al., 2006; Xu et al., 2010).

Vascular endothelial (VE)-cadherin at endothelial cell-cell junctions and integrin-ECM interactions modulate VEGFR2 and VEGFR3 signaling in response to fluid flow-induced biomechanical stimuli (Chen et al., 2010; Coon et al., 2015). Integrins have also been shown to interact with VEGFR2 that is activated by matrix-bound VEGFA isoforms, which increases VEGFR2 phosphorylation and downstream signaling (Chen et al., 2010). The VEGFR2/integrin association is mediated by the tetraspanin CD63 (Tugues et al., 2013). Integrins can also promote ligand-independent VEGFR activation upon cell adhesion to the ECM (Galvagni et al., 2010).

Intracellular trafficking of VEGF-VEGFR complexes modulates their signaling. For example, growth factor-mediated activation of VEGFRs induces ephrin B2-dependent endocytosis of the ligandreceptor complexes, which is important for spatial control and full activation of various downstream signaling pathways (Sawamiphak et al., 2010; Wang et al., 2010). In particular, the deletion of Efnb2 decreases VEGFC-stimulated phosphorylation of VEGFR3, the serine/threonine protein kinase AKT and the mitogen-activated protein kinase ERK1/2, as well as VEGFA-stimulated VEGFR2 phosphorylation.

\section{Signaling downstream of VEGFRs}

Successful ligand-stimulated dimerization leads to the autophosphorylation of specific tyrosine residues located in the intracellular juxtamembrane domain, the kinase domain and the C-terminal tail of VEGFRs. These phosphotyrosine residues then serve as docking sites for downstream signaling molecules that regulate cellular responses. Activated VEGFR2, for example, is phosphorylated on multiple tyrosine residues, and the phosphorylation results in biological responses such as proliferation, migration, survival and permeability (reviewed by Simons et al., 2016). The major phosphorylation sites in VEGFR2 are Tyr951 in the kinase insert domain and Tyr1175 in the C-terminal domain. Phosphorylated Tyr951 mediates TSAd adaptor proteindependent SRC tyrosine kinase activation, which in turn regulates vascular permeability through VE-cadherin phosphorylation and internalization ( $\mathrm{Li}$ et al., 2016). By contrast, phosphorylated Tyr1175 recruits PLC $\gamma$ to the plasma membrane and triggers the hydrolysis of phosphatidylinositol-4,5-bisphosphate to diacylglycerol (DAG) and inositol 1,4,5-triphosphate $\left[\mathrm{IP}_{3}\right.$; $\left.\operatorname{Ins}(1,4,5) \mathrm{P}_{3}\right]$ (Takahashi et al., 2001). This then activates the ERK and $\mathrm{Ca}^{2+}$-signaling pathways, and regulates endothelial cell proliferation and migration. Additional phosphorylation sites in VEGFR2 have been reported, but their role is still unclear (Matsumoto et al., 2005). For further details, the reader is referred to a recent review (Simons et al., 2016).

Several phosphotyrosine residues have also been reported in VEGFR1, although its kinase activity is low (apparently owing to a repressor sequence in the juxtamembrane domain) and it does not seem to promote ligand-stimulated cell migration or mitogenesis in endothelial cells (Gille et al., 2000; Ito et al., 1998). However, VEGFR1 is expressed in monocyte/macrophage-lineage cells and its signaling promotes mobilization of macrophage lineage cells from bone marrow and modulates the function of sensory nerves (Muramatsu et al., 2010; Sawano et al., 2001; Selvaraj et al., 2015). VEGFR3 is also phosphorylated following activation, leading to downstream signaling events. In particular, it has been shown that VEGFC-induced VEGFR3 activation leads to phosphorylation of the serine/threonine kinases AKT and ERK, which promote lymphatic endothelial cell (LEC) proliferation, migration and survival (Makinen et al., 2001; Salameh et al., 2005).

\section{VEGFR signaling in blood vessels}

Angiogenesis, the formation of new blood vessels from pre-existing ones, is mediated mainly by VEGFA/VEGFR2 signaling. In this context, VEGFA induces endothelial proliferation, migration and survival via activation of VEGFR2 and its downstream signal transduction pathways. By contrast, VEGFR1, which has a higher affinity for VEGFA but possesses weak tyrosine kinase activity, acts as an anti-angiogenic decoy receptor on the endothelial cell surface or in a soluble form (Shibuya and Claesson-Welsh, 2006). In line with this, the VEGFR1-specific ligands VEGFB and PLGF do not, in general, recapitulate many of the VEGFA effects (Gerber et al., 1998). VEGFR3 is also expressed in angiogenic endothelial cells, where it is important for the 'tip cell' phenotype of sprouting vessels (Tammela et al., 2011, 2008). Furthermore, macrophage-derived VEGFC, which acts as a ligand for VEGFR3, seems to participate in the fusion of vessel sprouts during the development of the retinal vasculature (Tammela et al., 2011).

Several insights into VEGF signaling have come from studies of angiogenesis in the developing mouse retina. Retinal angiogenesis follows a highly ordered sequence of events, which rely on VEGFA/VEGFR2 signaling and on hypoxia-regulated growth factor gradients formed by different VEGFA isoforms. Mice in which only a single VEGFA isoform $\left(\mathrm{VEGFA}_{120}, \mathrm{VEGFA}_{164}\right.$ or VEGFA $_{188}$ ) is expressed have distinct vascular phenotypes (Stalmans et al., 2002). Guidance cues from the cell- and matrix-bound VEGF isoforms provide spatial information on where the vessels need to develop in specific patterns. Postnatal deletion of Vegf or Vegfr2, or the disruption of their interaction, is sufficient to arrest retinal vascular growth, whereas postnatal deletion of Vegfrl results in increased angiogenesis (Gerhardt et al., 2003; Ho and Fong, 2015). Interestingly, postnatal deletion of Vegfr3 increases VEGFR2 levels (Heinolainen et al., 2017; Zarkada et al., 2015), resulting in hypersprouting and hyperbranching 
of the retinal vasculature (Tammela et al., 2011), which is mediated by VEGFR2 (Zarkada et al., 2015).

In addition to regulating blood vessel formation, VEGF signaling can control vessel permeability (Nagy et al., 2012). VEGFAinduced blood vessel permeability, in particular, is crucial for physiological and pathological processes. The binding of VEGFA to VEGFR2 recruits the TSAd adapter protein complex, which regulates VEGFA-induced activation of the tyrosine kinase Src and vascular permeability ( $\mathrm{Li}$ et al., 2016; Sun et al., 2012). Activation of Src also regulates focal adhesion kinase-mediated cell-matrix adhesion, contributing to the permeability effect (Chen et al., 2012). By contrast, angiopoietin 1, which binds to and activates the receptor Tie2 on endothelial cells, can suppress permeability via Diaph-mediated sequestration of Src (Gavard et al., 2008). Interestingly, it was recently shown that VEGFR3 is essential for keeping VEGFR2 expression under control, thereby modulating VEGFA/VEGFR2 signaling and hence vascular permeability in blood vascular endothelial cells (Heinolainen et al., 2017).

\section{VEGFR signaling in lymphatic vessels}

The lymphatic vascular network consists of initial absorptive lymphatic capillaries, which drain into pre-collectors that contain valves but lack smooth muscle cell coverage, eventually ending up in collecting lymphatic vessels, which are endowed with a continuous basement membrane and smooth muscle cell coverage (Karaman et al., 2017). Lymphangiogenesis - the growth of lymphatic vessels from pre-existing ones - occurs mainly in response to VEGFCinduced VEGFR3 activation (Karkkainen et al., 2004). VEGFA, in addition to inducing angiogenesis, can also stimulate lymphatic vessel expansion (Nagy et al., 2002; Wirzenius et al., 2007). Despite its similarity to VEGFC, VEGFD is dispensable for developmental lymphangiogenesis in mammals (Baldwin et al., 2005), although its absence leads to somewhat decreased lymphatic vessel caliber in the skin (Paquet-Fifield et al., 2013) and inhibition of facial lymphangiogenesis in zebrafish (Bower et al., 2017).

The first lymphatic endothelial progenitors in mouse embryos egress as streams of cells from the roof of the cardinal vein at embryonic day (E) 10.25 (Hägerling et al., 2013). Alternative nonvenous lymphatic endothelial progenitors have also been suggested to exist (Mahadevan et al., 2014), and this concept has been corroborated by genetic lineage-tracing experiments (Klotz et al., 2015; Martinez-Corral et al., 2015; Nicenboim et al., 2015; Stanczuk et al., 2015). The essential role of VEGFC in inducing the migration of LECs has been shown in $V e g f c$-deficient embryos, where LECs fail to detach from the cardinal vein to form the dorsal peripheral longitudinal lymphatic vessel (PLLV) and the ventral primordial thoracic duct (pTD), which leads to embryonic lethality between E15.5 and E17.5 (Hägerling et al., 2013; Karkkainen et al., 2004). In contrast, mice with a Vegfr 3 deletion die at around E10.5 due to defects in cardiovascular development (Dumont et al., 1998).

VEGFC/VEGFR3 signaling also plays a role in regulating the remodeling and homeostasis of lymphatic vessels. For example, VEGFC can induce lymphangiogenesis via VEGFR3 and enhance contractions of collecting lymphatic vessels via their surrounding smooth muscle cells (Jeltsch et al. 1997; Gogineni et al., 2013). Recently, the matrix-binding adapter protein CCBE1 and the ADAMTS3 metalloprotease were shown to be essential for proteolytic activation of VEGFC, thereby potentiating its full range of effects (Jeltsch et al., 2014; Roukens et al., 2015). It has also been shown that VEGFR3 stimulation protects LECs from apoptosis and induces their growth and migration (Makinen et al., 2001). In adult mice, most lymphatic vessels are independent of VEGFC/VEGFR3 signaling, which is however necessary for the maintenance of the absorptive intestinal lymphatic vessels (lacteals) and meningeal lymphatic vessels (Antila et al., 2017; Nurmi et al., 2015).

\section{VEGF signaling and its inhibition in disease}

VEGF/VEGFR signaling has been implicated in pathogenesis of several diseases. For example, VEGFA promotes angiogenesis, disruption of the blood-retinal barrier, inflammation and vision loss in individuals with ocular diseases such as retinopathy of prematurity, diabetic retinopathy and the wet form of age-related macular degeneration (Ferrara and Adamis, 2016). VEGFR1 and its soluble form of VEGFR1 (sVEGFR1) act as endogenous inhibitors of VEGFA/VEGFR2 signaling, thus VEGFR1 mis-regulation can also participate in pathological processes. Indeed, epithelial sVEGFR1 expression has been claimed to contribute to the avascularity and transparency of the cornea in the eye (Ambati et al., 2006). It has also been shown that the placenta produces high levels of sVEGFR1 during pregnancy, and the pathogenesis of pre-eclampsia during the last trimester has been linked to sVEGFR1 neutralization of VEGFA and PLGF (Koga et al., 2003; Maynard et al., 2003).

In addition to endothelial cells, VEGFs and VEGF receptors are expressed in non-endothelial cells, including some tumor cells. VEGFA secreted by tumor cells stimulates the proliferation and survival of endothelial cells, leading to the formation of new blood vessels, which promotes tumor expansion (reviewed by Ferrara and Adamis, 2016). In part because of the excessive VEGFA levels expressed by hypoxic tumor cells, tumor vessels are organized in a chaotic fashion instead of the hierarchical branching pattern found in normal vascular networks (reviewed by Jain, 2003). The development and use of neutralizing antibodies to VEGFA produced the first direct evidence that tumor growth depends on angiogenesis and confirmed the importance of VEGFA in this process (Kim et al., 1993). However, the benefit of monotherapy directed to VEGFA is limited to some tumor types, and the therapy in general does not prolong overall patient survival (Prenen et al., 2013). Currently, vigorous clinical trial activity is focused mainly on combination therapies, including the use of VEGF- and immune checkpoint-neutralizing antibodies (Khan and Kerbel, 2018). Although tumor-associated lymphatic vessels have been validated as therapeutic targets for metastasis inhibition, antibodies against VEGFR3 have so far been tested only in a phase I clinical trial (Dieterich and Detmar, 2016).

Aberrant VEGF signaling has also been linked to several pathological processes in the eye. Corneal transparency in the eye depends on strict vascular demarcation; in healthy corneas, neither blood nor lymphatic vessels cross the limbus, allowing the cornea to maintain an avascular state (Beebe, 2008). Pathological angiogenesis and lymphangiogenesis are associated with corneal inflammation (Bock et al., 2013). VEGFC signaling controls the development of Schlemm's canal, which is a specialized hybrid vessel structure that leads aqueous humor from the anterior chamber of the eye into venous circulation, regulating intraocular pressure (Aspelund et al., 2014; Park et al., 2014). Genetic deletion of $V e g f c$ or $V e g f r 3$, or the use of VEGFR3 signaling blockers, inhibit Schlemm's canal development and function, whereas VEGFC injection into the anterior chamber of the eye leads to Schlemm's canal expansion and decrease of intraocular pressure (Aspelund et al., 2014).

The VEGF pathway has also been linked to lymphedema, which is characterized by excessive accumulation of protein-rich extracellular fluid in the interstitial space due to impaired lymphatic vessel function. Primary lymphedema can be caused by a genetic disease, 
such as Nonne-Milroy disease, whereas secondary lymphedema is commonly caused by filariasis (roundworm infection) in developing countries and by complications of surgery in individuals with cancer. Individuals with Nonne-Milroy disease have tyrosine kinase-inactivating mutations in one VEGFR3 allele, and heterozygous mutations in $V E G F C$ are linked to a Milroy-like primary lymphedema (Gordon et al., 2013; Irrthum et al., 2000; Karkkainen et al., 2000). Moreover, mutations in the $C C B E 1$ and $A D A M T S 3$ genes have been linked to Hennekam syndrome, which also involves lymphedema (Alders et al., 2009; Brouillard et al., 2017; Jha et al., 2017). Because of the key involvement of VEGFC/VEGFR3 signaling in the pathogenesis of lymphedema, a phase I clinical trial (NCT02994771) has been started, in which VEGFC gene therapy is used to repair damaged lymphatic vessels after lymphadenectomy in individuals with breast cancer who developed lymphedema of the ipsilateral arm.

The recent discovery of lymphatic vessels in the meningeal tissues surrounding the central nervous system (CNS) has raised interest in their possible contribution to neurological diseases (Aspelund et al., 2015; Louveau et al., 2015; Ma et al., 2017). Of note, it has recently been demonstrated that meningeal lymphatic vessels develop postnatally following VEGFC expression by smoothmuscle cells around the blood vessels, and that they retain VEGFR3 signaling dependence in adults (Antila et al., 2017). This suggests that targeting the VEGFC pathway could provide a means of modulating the function and drainage capacity of meningeal lymphatic vessels in the prevention or treatment of neuropathological conditions.

\section{Conclusions}

During the past few decades, it has been established that angiogenesis is essential for embryonic development and homeostasis in adults, as well as for the progression of cancer and other diseases. More recently, lymphangiogenesis was also shown to be essential for embryonic development, and to be involved in many pathological processes such as lymphedema, inflammatory diseases and tumor metastasis. Our knowledge of the circulatory system in general and of the molecular mechanisms controlling angiogenesis and lymphangiogenesis has improved considerably due to progress in the identification of regulatory molecules and markers specific to the blood vascular and lymphatic endothelium. These studies have highlighted the pivotal roles of the VEGFA/VEGFR2 and VEGFC/VEGFR3 signaling axes in angiogenesis and lymphangiogenesis, respectively. In addition, it is now known that multiple co-receptors and accessory molecules regulate the signaling downstream of these crucial pathways. Despite these achievements, there are still many intriguing questions to be addressed and preliminary findings to be confirmed. For example, it is becoming clear that VEGFR2 and VEGFR3 are not entirely specific to blood or lymphatic vasculature, but function - in part redundantly - in both systems. Although their signaling functions seem to involve heterodimerization at the ligand and receptor levels, it is not clear whether this is significant in vivo. In addition to the co-receptors and accessory molecules presented here, there are many other potential regulators of VEGFR signaling that need to be mechanistically validated. Major disease-related issues concern the improvement of anti-angiogenic therapy in cancer, and possibilities to develop pro-angiogenic and -lymphangiogenic therapies. The discovery of meningeal lymphatics vessels and their dependence on VEGF signaling could provide therapeutic approaches for the treatment of individuals suffering from neurological diseases. Looking ahead, the resolution of these and other issues require improved understanding of VEGFR function and signaling during development and disease, which should provide successful therapeutic targeting of the vascular system in an expanding spectrum of human pathologies.

\section{Acknowledgements}

We apologize to all authors whose work could not be cited due to space limitations We thank Dr Lena Claesson-Welsh (Uppsala University, Uppsala, Sweden) and Dr Michael Jeltsch (Wihuri Research Institute and University of Helsinki, Helsinki, Finland) for their critical comments on the manuscript.

\section{Competing interests}

The authors declare no competing or financial interests.

\section{Funding}

We gratefully acknowledge funding from the Jane ja Aatos Erkon Säätiö (Jane and Aatos Erkko Foundation), the European Research Council (ERC) under the European Union's Horizon 2020 research and innovation program (743155), the Jenny ja Antti Wihurin Rahasto (Wihuri Foundation), the Suomen Akatemia (Academy of Finland) Centre of Excellence Program 2014-2019 (307366), the Fondation Leducq (11CVD03), the Novo Nordisk Fonden (Novo Nordisk Foundation) and the Sigrid Juséliuksen Säätiöltä (Sigrid Jusélius Foundation) (all to K.A.). S.K. was supported by the Schweizerischer Nationalfonds zur Förderung der Wissenschaftlichen Forschung (Swiss National Science Foundation) (Advanced Postdoc Mobility grant number P300PB_164732) and the Orionin Tutkimussäätiön (Orion Research Foundation).

\section{Development at a Glance}

A high-resolution version of the poster is available for downloading in the online version of this article at http://dev.biologists.org/content/145/14/dev151019/F1. poster.jpg

\section{References}

Alders, M., Hogan, B. M., Gjini, E., Salehi, F., Al-Gazali, L., Hennekam, E. A., Holmberg, E. E., Mannens, M. M. A. M., Mulder, M. F., Offerhaus, G. J. A. et al. (2009). Mutations in CCBE1 cause generalized lymph vessel dysplasia in humans. Nat. Genet. 41, 1272-1274.

Ambati, B. K., Nozaki, M., Singh, N., Takeda, A., Jani, P. D., Suthar, T. Albuquerque, R. J. C., Richter, E., Sakurai, E., Newcomb, M. T. et al. (2006). Corneal avascularity is due to soluble VEGF receptor-1. Nature 443, 993-997.

Anisimov, A., Leppanen, V.-M., Tvorogov, D., Zarkada, G., Jeltsch, M., Holopainen, T., Kaijalainen, S. and Alitalo, K. (2013). The basis for the distinct biological activities of vascular endothelial growth factor receptor-1 ligands. Sci. Signal. 6, ra52.

Antila, S., Karaman, S., Nurmi, H., Airavaara, M., Voutilainen, M. H., Mathivet, T., Chilov, D., Li, Z., Koppinen, T., Park, J.-H. et al. (2017). Development and plasticity of meningeal lymphatic vessels. J. Exp. Med. 214, 3645-3667.

Aspelund, A., Tammela, T., Antila, S., Nurmi, H., Leppänen, V.-M., Zarkada, G., Stanczuk, L., Francois, M., Mäkinen, T., Saharinen, P. et al. (2014). The Schlemm's canal is a VEGF-C/VEGFR-3-responsive lymphatic-like vessel. J. Clin. Invest. 124, 3975-3986.

Aspelund, A., Antila, S., Proulx, S. T., Karlsen, T. V., Karaman, S., Detmar, M., Wiig, H. and Alitalo, K. (2015). A dural lymphatic vascular system that drains brain interstitial fluid and macromolecules. J. Exp. Med. 212, 991-999.

Baldwin, M. E., Halford, M. M., Roufail, S., Williams, R. A., Hibbs, M. L., Grail, D., Kubo, H., Stacker, S. A. and Achen, M. G. (2005). Vascular endothelial growth factor $\mathrm{D}$ is dispensable for development of the lymphatic system. Mol. Cell. Biol. 25, 2441-2449.

Becker, P. M., Waltenberger, J., Yachechko, R., Mirzapoiazova, T., Sham, J. S., Lee, C. G., Elias, J. A. and Verin, A. D. (2005). Neuropilin-1 regulates vascular endothelial growth factor-mediated endothelial permeability. Circ. Res. 96 1257-1265.

Beebe, D. C. (2008). Maintaining transparency: a review of the developmental physiology and pathophysiology of two avascular tissues. Semin. Cell Dev. Biol. 19, 125-133

Bock, F., Maruyama, K., Regenfuss, B., Hos, D., Steven, P., Heindl, L. M. and Cursiefen, C. (2013). Novel anti(lymph)angiogenic treatment strategies for corneal and ocular surface diseases. Prog. Retin. Eye Res. 34, 89-124.

Bower, N. I., Vogrin, A. J., Le Guen, L., Chen, H., Stacker, S. A., Achen, M. G. and Hogan, B. M. (2017). Vegfd modulates both angiogenesis and lymphangiogenesis during zebrafish embryonic development. Development 144, 507-518.

Brouillard, P., Dupont, L., Helaers, R., Coulie, R., Tiller, G. E., Peeden, J., Colige, A. and Vikkula, M. (2017). Loss of ADAMTS3 activity causes Hennekam lymphangiectasia-lymphedema syndrome 3. Hum. Mol. Genet. 26, 4095-4104.

Bui, H. M., Enis, D., Robciuc, M. R., Nurmi, H. J., Cohen, J., Chen, M., Yang, Y., Dhillon, V., Johnson, K., Zhang, H. et al. (2016). Proteolytic activation defines 
distinct lymphangiogenic mechanisms for VEGFC and VEGFD. J. Clin. Invest 126, 2167-2180

Cao, Y., Chen, H., Zhou, L., Chiang, M.-K., Anand-Apte, B., Weatherbee, J. A. Wang, Y., Fang, F., Flanagan, J. G. and Tsang, M. L.-S. (1996). Heterodimers of placenta growth factor/vascular endothelial growth factor. J. Biol. Chem. 271, 3154-3162.

Chen, T. T., Luque, A., Lee, S., Anderson, S. M., Segura, T. and Iruela-Arispe M. L. (2010). Anchorage of VEGF to the extracellular matrix conveys differential signaling responses to endothelial cells. J. Cell Biol. 188, 595-609.

Chen, X. L., Nam, J.-O., Jean, C., Lawson, C., Walsh, C. T., Goka, E., Lim, S.-T., Tomar, A., Tancioni, I., Uryu, S. et al. (2012). VEGF-induced vascular permeability is mediated by FAK. Dev. Cell 22, 146-157

Coon, B. G., Baeyens, N., Han, J., Budatha, M., Ross, T. D., Fang, J. S., Yun, S. Thomas, J.-L. and Schwartz, M. A. (2015). Intramembrane binding of VE-cadherin to VEGFR2 and VEGFR3 assembles the endothelial mechanosensory complex. J. Cell Biol. 208, 975-986.

Cudmore, M. J., Hewett, P. W., Ahmad, S., Wang, K.-Q., Cai, M., Al-Ani, B., Fujisawa, T., Ma, B., Sissaoui, S., Ramma, W. et al. (2012). The role of heterodimerization between VEGFR-1 and VEGFR-2 in the regulation of endothelial cell homeostasis. Nat. Commun. 3, 972

Dieterich, L. C. and Detmar, M. (2016). Tumor lymphangiogenesis and new drug development. Adv. Drug Deliv. Rev. 99, 148-160.

Dixelius, J., Mäkinen, T., Wirzenius, M., Karkkainen, M. J., Wernstedt, C. Alitalo, K. and Claesson-Welsh, L. (2003). Ligand-induced vascular endothelia growth factor receptor-3 (VEGFR-3) heterodimerization with VEGFR-2 in primary lymphatic endothelial cells regulates tyrosine phosphorylation sites. J. Biol. Chem 278, 40973-40979.

Dumont, D. J., Jussila, L., Taipale, J., Lymboussaki, A., Mustonen, T., Pajusola, K., Breitman, M. and Alitalo, K. (1998). Cardiovascular failure in mouse embryos deficient in VEGF receptor-3. Science 282, 946-949.

Eilken, H. M., Diéguez-Hurtado, R., Schmidt, I., Nakayama, M., Jeong, H.-W., Arf, H., Adams, S., Ferrara, N. and Adams, R. H. (2017). Pericytes regulate VEGF-induced endothelial sprouting through VEGFR1. Nat. Commun. 8, 1574.

Fantin, A., Lampropoulou, A., Senatore, V., Brash, J. T., Prahst, C., Lange, C. A. Liyanage, S. E., Raimondi, C., Bainbridge, J. W., Augustin, H. G. et al. (2017) VEGF165-induced vascular permeability requires NRP1 for ABL-mediated SRC family kinase activation. J. Exp. Med. 214, 1049-1064.

Ferrara, N. and Adamis, A. P. (2016). Ten years of anti-vascular endothelial growth factor therapy. Nat. Rev. Drug Discov. 15, 385-403.

Galvagni, F., Pennacchini, S., Salameh, A., Rocchigiani, M., Neri, F., Orlandini, M., Petraglia, F., Gotta, S., Sardone, G. L., Matteucci, G. et al. (2010). Endothelial cell adhesion to the extracellular matrix induces c-Src-dependent VEGFR-3 phosphorylation without the activation of the receptor intrinsic kinase activity. Circ. Res. 106, 1839-1848.

Gavard, J., Patel, V. and Gutkind, J. S. (2008). Angiopoietin-1 prevents VEGF-induced endothelial permeability by sequestering Src through $\mathrm{mDia}$ Dev. Cell 14, 25-36.

Gerber, H. P., McMurtrey, A., Kowalski, J., Yan, M., Keyt, B. A., Dixit, V. and Ferrara, N. (1998). Vascular endothelial growth factor regulates endothelia cell survival through the phosphatidylinositol 3'-kinase/Akt signal transduction pathway. Requirement for Flk-1/KDR activation. J. Biol. Chem. 273 30336-30343.

Gerhardt, H., Golding, M., Fruttiger, M., Ruhrberg, C., Lundkvist, A., Abramsson, A., Jeltsch, M., Mitchell, C., Alitalo, K., Shima, D. et al. (2003) VEGF guides angiogenic sprouting utilizing endothelial tip cell filopodia. J. Cell Biol. 161, 1163-1177.

Gille, H., Kowalski, J., Yu, L., Chen, H., Pisabarro, M. T., Davis-Smyth, T. and Ferrara, N. (2000). A repressor sequence in the juxtamembrane domain of Flt-1 (VEGFR-1) constitutively inhibits vascular endothelial growth factor-dependent phosphatidylinositol 3'-kinase activation and endothelial cell migration. EMBO J. 19, 4064-4073.

Gogineni, A., Caunt, M., Crow, A., Lee, C. V., Fuh, G., van Bruggen, N., Ye, W. and Weimer, R. M. (2013). Inhibition of VEGF-C modulates distal lymphatic remodeling and secondary metastasis. PLOS ONE 8, e68755

Gordon, K., Schulte, D., Brice, G., Simpson, M. A., Roukens, M. G., van Impel, A., Connell, F., Kalidas, K., Jeffery, S., Mortimer, P. S. et al (2013). Mutation in vascular endothelial growth factor-C, a ligand for vascular endothelial growth factor receptor-3, is associated with autosomal dominant milroy-like primary lymphedema. Circ. Res. 112, 956-960.

Hägerling, R., Pollmann, C., Andreas, M., Schmidt, C., Nurmi, H., Adams, R. H. Alitalo, K., Andresen, V., Schulte-Merker, S. and Kiefer, F. (2013). A nove multistep mechanism for initial lymphangiogenesis in mouse embryos based on ultramicroscopy. EMBO J. 32, 629-644.

Harris, S., Craze, M., Newton, J., Fisher, M., Shima, D. T., Tozer, G. M. and Kanthou, C. (2012). Do anti-angiogenic VEGF (VEGFxxxb) isoforms exist? A cautionary tale. PLOS ONE 7, e35231.

Heinolainen, K., Karaman, S., D’Amico, G., Tammela, T., Sormunen, R., Eklund, L., Alitalo, K. and Zarkada, G. (2017). VEGFR3 modulates vascular permeability by controlling VEGF/NEGFR2 signaling. Circ. Res. 120, 1414-1425.
Hiratsuka, S., Minowa, O., Kuno, J., Noda, T. and Shibuya, M. (1998). Flt-1 lacking the tyrosine kinase domain is sufficient for normal development and angiogenesis in mice. Proc. Natl. Acad. Sci. USA 95, 9349-9354

Ho, V. C. and Fong, G.-H. (2015). Vasculogenesis and angiogenesis in VEGF receptor-1 deficient mice. Methods Mol. Biol. 1332, 161-176.

Houck, K. A., Leung, D. W., Rowland, A. M., Winer, J. and Ferrara, N. (1992). Dual regulation of vascular endothelial growth factor bioavailability by genetic and proteolytic mechanisms. J. Biol. Chem. 267, 26031-26037.

Huang, K., Andersson, C., Roomans, G. M., Ito, N. and Claesson-Welsh, L. (2001). Signaling properties of VEGF receptor-1 and -2 homo- and heterodimers. Int. J. Biochem. Cell Biol. 33, 315-324.

Irrthum, A., Karkkainen, M. J., Devriendt, K., Alitalo, K. and Vikkula, M. (2000) Congenital hereditary lymphedema caused by a mutation that inactivates VEGFR3 tyrosine kinase. Am. J. Hum. Genet. 67, 295-301.

Ito, N., Wernstedt, C., Engström, U. and Claesson-Welsh, L. (1998). Identification of vascular endothelial growth factor receptor-1 tyrosine phosphorylation sites and binding of SH2 domain-containing molecules. J. Biol. Chem. 273, 23410-23418. Jain, R. K. (2003). Molecular regulation of vessel maturation. Nat. Med. 9, 685-693. Jeltsch M., Kaipainen, A., Joukov, V., Meng, X., Lakso, M., Rauvala, H., Swartz, M., Fukumura, D., Jain, R. K. and Alitalo, K. (1997). Hyperplasia of lymphatic vessels in VEGF-C transgenic mice. Science 276, 1423-1425.

Jeltsch, M., Jha, S. K., Tvorogov, D., Anisimov, A., Leppanen, V.-M., Holopainen, T., Kivela, R., Ortega, S., Karpanen, T. and Alitalo, K. (2014) CCBE1 enhances lymphangiogenesis via A disintegrin and metalloprotease with thrombospondin motifs-3-mediated vascular endothelial growth factor-C activation. Circulation 129, 1962-1971.

Jha, S. K., Rauniyar, K., Karpanen, T., Leppänen, V.-M., Brouillard, P., Vikkula, M., Alitalo, K. and Jeltsch, M. (2017). Efficient activation of the lymphangiogenic growth factor VEGF-C requires the C-terminal domain of VEGF-C and the N-terminal domain of CCBE1. Sci. Rep. 7, 4916

Johns, S. C., Yin, X., Jeltsch, M., Bishop, J. R., Schuksz, M., El Ghazal, R., Wilcox-Adelman, S. A., Alitalo, K. and Fuster, M. M. (2016). Functional Importance of a Proteoglycan Coreceptor in Pathologic Lymphangiogenesis. Circ. Res. 119, 210-221.

Joukov, V., Sorsa, T., Kumar, V., Jeltsch, M., Claesson-Welsh, L., Cao, Y., Saksela, O., Kalkkinen, N. and Alitalo, K. (1997). Proteolytic processing regulates receptor specificity and activity of VEGF-C. EMBO J. 16, 3898-3911.

Karaman, S., Aspelund, A., Detmar, M. and Alitalo, K. (2017). The lymphatic system. In ESC Textbook in Vascular Biology. Oxford, UK: Oxford University Press.

Karkkainen, M. J., Ferrell, R. E., Lawrence, E. C., Kimak, M. A., Levinson, K. L., McTigue, M. A., Alitalo, K. and Finegold, D. N. (2000). Missense mutations interfere with VEGFR-3 signalling in primary lymphoedema. Nat. Genet. 25, 153-159

Karkkainen, M. J., Haiko, P., Sainio, K., Partanen, J., Taipale, J., Petrova, T. V., Jeltsch, M., Jackson, D. G., Talikka, M., Rauvala, H. et al. (2004). Vascular endothelial growth factor $\mathrm{C}$ is required for sprouting of the first lymphatic vessels from embryonic veins. Nat. Immunol. 5, 74-80.

Kärpänen, T., Heckman, C. A., Keskitalo, S., Jeltsch, M., Ollila, H., Neufeld, G., Tamagnone, L. and Alitalo, K. (2006). Functional interaction of VEGF-C and VEGF-D with neuropilin receptors. FASEB J. 20, 1462-1472.

Kendall, R. L. and Thomas, K. A. (1993). Inhibition of vascular endothelial cell growth factor activity by an endogenously encoded soluble receptor. Proc. Natl. Acad. Sci. USA 90, 10705-10709.

Kendrew, J., Eberlein, C., Hedberg, B., McDaid, K., Smith, N. R., Weir, H. M. Wedge, S. R., Blakey, D. C., Foltz, I., Zhou, J. et al. (2011). An antibody targeted to VEGFR-2 Ig domains 4-7 inhibits VEGFR-2 activation and VEGFR-2 dependent angiogenesis without affecting ligand binding. Mol. Cancer Ther. 10 770-783.

Khan, K. A. and Kerbel, R. S. (2018). Improving immunotherapy outcomes with anti-angiogenic treatments and vice versa. Nat. Rev. Clin. Oncol. 15, 310-324.

Kim, K. J., Li, B., Winer, J., Armanini, M., Gillett, N., Phillips, H. S. and Ferrara, N. (1993). Inhibition of vascular endothelial growth factor-induced angiogenesis suppresses tumour growth in vivo. Nature 362, 841

Kivela, R., Bry, M., Robciuc, M. R., Rasanen, M., Taavitsainen, M. Silvola, J. M. U., Saraste, A., Hulmi, J. J., Anisimov, A., Mayranpaa, M. I. et al. (2014). VEGF-B-induced vascular growth leads to metabolic reprogramming and ischemia resistance in the heart. EMBO Mol. Med. 6, 307-321.

Klotz, L., Norman, S., Vieira, J. M., Masters, M., Rohling, M., Dubé, K. N. Bollini, S., Matsuzaki, F., Carr, C. A. and Riley, P. R. (2015). Cardiac lymphatics are heterogeneous in origin and respond to injury. Nature 522, 62

Koga, K., Osuga, Y., Yoshino, O., Hirota, Y., Ruimeng, X., Hirata, T., Takeda, S., Yano, T., Tsutsumi, O. and Taketani, Y. (2003). Elevated serum soluble vascula endothelial growth factor receptor 1 (sVEGFR-1) levels in women with preeclampsia. J. Clin. Endocrinol. Metab. 88, 2348-2351.

Le Guen, L., Karpanen, T., Schulte, D., Harris, N. C., Koltowska, K. Roukens, G., Bower, N. I., van Impel, A., Stacker, S. A., Achen, M. G. et al. (2014). Ccbe1 regulates Vegfc-mediated induction of Vegfr3 signaling during embryonic lymphangiogenesis. Development 141, 1239-1249. 
Lee, S., Jilani, S. M., Nikolova, G. V., Carpizo, D. and Iruela-Arispe, M. L. (2005). Processing of VEGF-A by matrix metalloproteinases regulates bioavailability and vascular patterning in tumors. J. Cell Biol. 169, 681-691.

Leppanen, V.-M., Tvorogov, D., Kisko, K., Prota, A. E., Jeltsch, M., Anisimov, A., Markovic-Mueller, S., Stuttfeld, E., Goldie, K. N., Ballmer-Hofer, K. et al. (2013). Structural and mechanistic insights into VEGF receptor 3 ligand binding and activation. Proc. Natl. Acad. Sci. USA 110, 12960-12965.

Leung, D. W., Cachianes, G., Kuang, W. J., Goeddel, D. V. and Ferrara, N. (1989) Vascular endothelial growth factor is a secreted angiogenic mitogen. Science 246, 1306-1309.

Li, X., Padhan, N., Sjöström, E. O., Roche, F. P., Testini, C., Honkura, N., Sáinz-Jaspeado, M., Gordon, E., Bentley, K., Philippides, A. et al. (2016) VEGFR2 pY949 signalling regulates adherens junction integrity and metastatic spread. Nat. Commun. 7, 11017.

Louveau, A., Smirnov, I., Keyes, T. J., Eccles, J. D., Rouhani, S. J., Peske, J. D. Derecki, N. C., Castle, D., Mandell, J. W., Lee, K. S. et al. (2015). Structural and functional features of central nervous system lymphatic vessels. Nature 523, 337-341.

Ma, Q., Ineichen, B. V., Detmar, M. and Proulx, S. T. (2017). Outflow of cerebrospinal fluid is predominantly through lymphatic vessels and is reduced in aged mice. Nat. Commun. 8, 1434

Maglione, D., Guerriero, V., Viglietto, G., Delli-Bovi, P. and Persico, M. G. (1991) Isolation of a human placenta cDNA coding for a protein related to the vascular permeability factor. Proc. Natl. Acad. Sci. USA 88, 9267-9271.

Mahadevan, A., Welsh, I. C., Sivakumar, A., Gludish, D. W., Shilvock, A. R. Noden, D. M., Huss, D., Lansford, R. and Kurpios, N. A. (2014). The left-right Pitx2 pathway drives organ-specific arterial and lymphatic development in the intestine. Dev. Cell 31, 690-706.

Makinen, T., Veikkola, T., Mustjoki, S., Karpanen, T., Catimel, B., Nice, E. C. Wise, L., Mercer, A., Kowalski, H., Kerjaschki, D. et al. (2001). Isolated lymphatic endothelial cells transduce growth, survival and migratory signals via the VEGF-C/D receptor VEGFR-3. EMBO J. 20, 4762-4773.

Markovic-Mueller, S., Stuttfeld, E., Asthana, M., Weinert, T., Bliven, S. Goldie, K. N., Kisko, K., Capitani, G. and Ballmer-Hofer, K. (2017). Structure of the full-length VEGFR-1 extracellular domain in complex with VEGF-A Structure 25, 341-352.

Martinez-Corral, I., Ulvmar, M. H., Stanczuk, L., Tatin, F., Kizhatil, K., John, S. W. M., Alitalo, K., Ortega, S. and Makinen, T. (2015). Nonvenous origin of dermal lymphatic vasculature. Circ. Res. 116, 1649-1654

Matsumoto, T., Bohman, S., Dixelius, J., Berge, T., Dimberg, A., Magnusson, P., Wang, L., Wikner, C., Qi, J. H., Wernstedt, C. et al. (2005). VEGF receptor-2 Y951 signaling and a role for the adapter molecule TSAd in tumor angiogenesis. EMBO J. 24, 2342-2353

Matthews, W., Jordan, C. T., Wiegand, G. W., Pardoll, D. and Lemischka, I. R. (1991). A receptor tyrosine kinase specific to hematopoietic stem and progenitor cell-enriched populations. Cell 65, 1143-1152.

Maynard, S. E., Min, J.-Y., Merchan, J., Lim, K.-H., Li, J., Mondal, S., Libermann, T. A., Morgan, J. P., Sellke, F. W., Stillman, I. E. et al. (2003) Excess placental soluble fms-like tyrosine kinase 1 (sFlt1) may contribute to endothelial dysfunction, hypertension, and proteinuria in preeclampsia. J. Clin. Invest. 111, 649-658

McColl, B. K., Baldwin, M. E., Roufail, S., Freeman, C., Moritz, R. L., Simpson, R. J., Alitalo, K., Stacker, S. A. and Achen, M. G. (2003). Plasmin activates the lymphangiogenic growth factors VEGF-C and VEGF-D. J. Exp. Med 198, 863-868.

Migdal, M., Huppertz, B., Tessler, S., Comforti, A., Shibuya, M., Reich, R. Baumann, H. and Neufeld, G. (1998). Neuropilin-1 is a placenta growth factor-2 receptor. J. Biol. Chem. 273, 22272-22278.

Muramatsu, M., Yamamoto, S., Osawa, T. and Shibuya, M. (2010). Vascular endothelial growth factor receptor-1 signaling promotes mobilization of macrophage lineage cells from bone marrow and stimulates solid tumor growth. Cancer Res. 70, 8211-8221.

Nagy, J. A., Vasile, E., Feng, D., Sundberg, C., Brown, L. F., Detmar, M. J., Lawitts, J. A., Benjamin, L., Tan, X., Manseau, E. J. et al. (2002). Vascula permeability factor/vascular endothelial growth factor induces lymphangiogenesis as well as angiogenesis. J. Exp. Med. 196, 1497-1506.

Nagy, J. A., Dvorak, A. M. and Dvorak, H. F. (2012). Vascular hyperpermeability, angiogenesis, and stroma generation. Cold Spring Harb. Perspect. Med. 2, a006544.

Nicenboim, J., Malkinson, G., Lupo, T., Asaf, L., Sela, Y., Mayseless, O., Gibbs-Bar, L., Senderovich, N., Hashimshony, T., Shin, M. et al. (2015). Lymphatic vessels arise from specialized angioblasts within a venous niche. Nature 522, 56

Nilsson, I., Bahram, F., Li, X., Gualandi, L., Koch, S., Jarvius, M., Söderberg, O. Anisimov, A., Kholová, I., Pytowski, B. et al. (2010). VEGF receptor 2/-3 heterodimers detected in situ by proximity ligation on angiogenic sprouts. $E M B O$ J. 29, 1377-1388.

Nurmi, H., Saharinen, P., Zarkada, G., Zheng, W., Robciuc, M. R. and Alitalo, K (2015). VEGF-C is required for intestinal lymphatic vessel maintenance and lipid absorption. EMBO Mol. Med. 7, 1418-1425.

Olofsson, B., Pajusola, K., Kaipainen, A., von Euler, G., Joukov, V., Saksela, O. Orpana, A., Pettersson, R. F., Alitalo, K. and Eriksson, U. (1996). Vascula endothelial growth factor B, a novel growth factor for endothelial cells. Proc. Natl. Acad. Sci. USA 93, 2576-2581.

Pajusola, K., Aprelikova, O., Korhonen, J., Kaipainen, A., Pertovaara, L., Alitalo, R. and Alitalo, K. (1992). FLT4 receptor tyrosine kinase contains seven immunoglobulin-like loops and is expressed in multiple human tissues and cell lines. Cancer Res. 52, 5738-5743.

Paquet-Fifield, S., Levy, S. M., Sato, T., Shayan, R., Karnezis, T., Davydova, N., Nowell, C. J., Roufail, S., Ma, G. Z.-M., Zhang, Y.-F. et al. (2013). Vascular endothelial growth factor-d modulates caliber and function of initial lymphatics in the dermis. J. Invest. Dermatol. 133, 2074-2084.

Park, J. E., Chen, H. H., Winer, J., Houck, K. A. and Ferrara, N. (1994). Placenta growth factor. Potentiation of vascular endothelial growth factor bioactivity, in vitro and in vivo, and high affinity binding to Flt-1 but not to Flk-1/KDR. J. Biol. Chem 269, 25646-25654.

Park, D.-Y., Lee, J., Park, I., Choi, D., Lee, S., Song, S., Hwang, Y., Hong, K. Y., Nakaoka, Y., Makinen, T. et al. (2014). Lymphatic regulator PROX1 determines Schlemm's canal integrity and identity. J. Clin. Invest. 124, 3960-3974.

Plouët, J., Moro, F., Bertagnolli, S., Coldeboeuf, N., Mazarguil, H., Clamens, S. and Bayard, F. (1997). Extracellular cleavage of the vascular endothelial growth factor 189-amino acid form by urokinase is required for its mitogenic effect. J. Biol. Chem. 272, 13390-13396.

Prenen, H., Vecchione, L. and Van Cutsem, E. (2013). Role of targeted agents in metastatic colorectal cancer. Target. Oncol. 8, 83-96.

Robciuc, M. R., Kivelä, R., Williams, I. M., de Boer, J. F., van Dijk, T. H. Elamaa, H., Tigistu-Sahle, F., Molotkov, D., Leppänen, V.-M., Käkelä, R. et al. (2016). VEGFB/VEGFR1-induced expansion of adipose vasculature counteracts obesity and related metabolic complications. Cell Metab. 23, 712-724.

Roukens, M. G., Peterson-Maduro, J., Padberg, Y., Jeltsch, M., Leppanen, V.-M., Bos, F. L., Alitalo, K., Schulte-Merker, S. and Schulte, D. (2015). Functional dissection of the CCBE1 protein: a crucial requirement for the collagen repeat domain. Circ. Res. 116, 1660-1669.

Salameh, A., Galvagni, F., Bardelli, M., Bussolino, F. and Oliviero, S. (2005) Direct recruitment of CRK and GRB2 to VEGFR-3 induces proliferation, migration, and survival of endothelial cells through the activation of ERK, AKT, and JNK pathways. Blood 106, 3423-3431.

Sarabipour, S., Ballmer-Hofer, K. and Hristova, K. (2016). VEGFR-2 conformational switch in response to ligand binding. eLife 5, e13876.

Sawamiphak, S., Seidel, S., Essmann, C. L., Wilkinson, G. A., Pitulescu, M. E. Acker, T. and Acker-Palmer, A. (2010). Ephrin-B2 regulates VEGFR2 function in developmental and tumour angiogenesis. Nature 465, 487-491.

Sawano, A., Iwai, S., Sakurai, Y., Ito, M., Shitara, K., Nakahata, T. and Shibuya, M. (2001). Flt-1, vascular endothelial growth factor receptor 1, is novel cell surface marker for the lineage of monocyte-macrophages in humans Blood 97, 785-791.

Selvaraj, D., Gangadharan, V., Michalski, C. W., Kurejova, M., Stösser, S., Srivastava, K., Schweizerhof, M., Waltenberger, J., Ferrara, N. Heppenstall, P. et al. (2015). A functional role for VEGFR1 expressed in peripheral sensory neurons in cancer pain. Cancer Cell 27, 780-796.

Senger, D. R., Galli, S. J., Dvorak, A. M., Perruzzi, C. A., Harvey, V. S. and Dvorak, H. F. (1983). Tumor cells secrete a vascular permeability factor that promotes accumulation of ascites fluid. Science 219, 983-985.

Shibuya, M. and Claesson-Welsh, L. (2006). Signal transduction by VEGF receptors in regulation of angiogenesis and lymphangiogenesis. Exp. Cell Res. 312, 549-560.

Shibuya, M., Yamaguchi, S., Yamane, A., Ikeda, T., Tojo, A., Matsushime, H. and Sato, M. (1990). Nucleotide sequence and expression of a novel human receptor-type tyrosine kinase gene (flt) closely related to the fms family. Oncogene 5, 519-524.

Simons, M., Gordon, E. and Claesson-Welsh, L. (2016). Mechanisms and regulation of endothelial VEGF receptor signalling. Nat. Rev. Mol. Cell Biol. 17 611-625.

Soker, S., Takashima, S., Miao, H. Q., Neufeld, G. and Klagsbrun, M. (1998) Neuropilin-1 is expressed by endothelial and tumor cells as an isoform-specific receptor for vascular endothelial growth factor. Cell 92, 735-745.

Stalmans, I., Ng, Y.-S., Rohan, R., Fruttiger, M., Bouché, A., Ÿuce, A., Fujisawa, H., Hermans, B., Shani, M., Jansen, S. et al. (2002). Arteriolar and venular patterning in retinas of mice selectively expressing VEGF isoforms. J. Clin. Invest. 109, 327-336.

Stanczuk, L., Martinez-Corral, I., Ulvmar, M. H., Zhang, Y., Laviña, B Fruttiger, M., Adams, R. H., Saur, D., Betsholtz, C., Ortega, S. et al. (2015) cKit lineage hemogenic endothelium-derived cells contribute to mesenteric lymphatic vessels. Cell reports 10, 1708-1721.

Sun, Z., Li, X., Massena, S., Kutschera, S., Padhan, N., Gualandi, L., Sundvold-Gjerstad, V., Gustafsson, K., Choy, W. W., Zang, G. et al. (2012) VEGFR2 induces c-Src signaling and vascular permeability in vivo via the adapto protein TSAd. J. Exp. Med. 209, 1363-1377.

Takahashi, T., Yamaguchi, S., Chida, K. and Shibuya, M. (2001). A single autophosphorylation site on KDR/Flk-1 is essential for VEGF-A-dependent activation of PLC-gamma and DNA synthesis in vascular endothelial cells. EMBO J. 20, 2768-2778. 
Tammela, T. and Alitalo, K. (2010). Lymphangiogenesis: molecular mechanisms and future promise. Cell 140, 460-476.

Tammela, T., Zarkada, G., Wallgard, E., Murtomäki, A., Suchting, S., Wirzenius, M., Waltari, M., Hellström, M., Schomber, T., Peltonen, R. et al. (2008). Blocking VEGFR-3 suppresses angiogenic sprouting and vascular network formation. Nature 454, 656-660.

Tammela, T., Zarkada, G., Nurmi, H., Jakobsson, L., Heinolainen, K., Tvorogov, D., Zheng, W., Franco, C. A., Murtomäki, A., Aranda, E. et al. (2011). VEGFR-3 controls tip to stalk conversion at vessel fusion sites by reinforcing Notch signalling. Nat. Cell Biol. 13, 1202-1213.

Teran, M. and Nugent, M. A. (2015). Synergistic binding of vascular endothelial growth factor-A and its receptors to heparin selectively modulates complex affinity. J. Biol. Chem. 290, 16451-16462.

Terman, B. I., Carrion, M. E., Kovacs, E., Rasmussen, B. A., Eddy, R. L. and Shows, T. B. (1991). Identification of a new endothelial cell growth factor receptor tyrosine kinase. Oncogene 6, 1677-1683.

Tugues, S., Honjo, S., König, C., Padhan, N., Kroon, J., Gualandi, L., Li, X., Barkefors, I., Thijssen, V. L., Griffioen, A. W. et al. (2013). Tetraspanin CD63 promotes vascular endothelial growth factor receptor 2-beta1 integrin complex formation, thereby regulating activation and downstream signaling in endothelial cells in vitro and in vivo. J. Biol. Chem. 288, 19060-19071.

Tvorogov, D., Anisimov, A., Zheng, W., Leppänen, V.-M., Tammela, T., Laurinavicius, S., Holnthoner, W., Heloterä, H., Holopainen, T., Jeltsch, M. et al. (2010). Effective suppression of vascular network formation by combination of antibodies blocking VEGFR ligand binding and receptor dimerization. Cancer Cell 18, 630-640.

Wang, Y., Nakayama, M., Pitulescu, M. E., Schmidt, T. S., Bochenek, M. L., Sakakibara, A., Adams, S., Davy, A., Deutsch, U., Lüthi, U. et al. (2010). Ephrin-B2 controls VEGF-induced angiogenesis and lymphangiogenesis. Nature 465, 483-486

Wirzenius, M., Tammela, T., Uutela, M., He, Y., Odorisio, T., Zambruno, G., Nagy, J. A., Dvorak, H. F., Ylä-Herttuala, S., Shibuya, M. et al. (2007). Distinct vascular endothelial growth factor signals for lymphatic vessel enlargement and sprouting. J. Exp. Med. 204, 1431-1440.

Xin, H., Zhong, C., Nudleman, E. and Ferrara, N. (2016). Evidence for pro-angiogenic functions of VEGF-Ax. Cell 167, 275-284.e276.

Xu, Y., Yuan, L., Mak, J., Pardanaud, L., Caunt, M., Kasman, I., Larrivée, B. del Toro, R., Suchting, S., Medvinsky, A. et al. (2010). Neuropilin-2 mediates VEGF-C-induced lymphatic sprouting together with VEGFR3. J. Cell Biol. 188, 115-130

Yang, Y., Xie, P., Opatowsky, Y. and Schlessinger, J. (2010). Direct contacts between extracellular membrane-proximal domains are required for VEGF receptor activation and cell signaling. Proc. Natl. Acad. Sci. USA 107, 1906-1911. Zarkada, G., Heinolainen, K., Makinen, T., Kubota, Y. and Alitalo, K. (2015). VEGFR3 does not sustain retinal angiogenesis without VEGFR2. Proc. Natl. Acad. Sci. USA 112, 761-766. 